This article was downloaded by: [Volker Janssen]

On: 11 December 2012, At: 01:41

Publisher: Routledge

Informa Ltd Registered in England and Wales Registered Number: 1072954 Registered

office: Mortimer House, 37-41 Mortimer Street, London W1T 3J H, UK

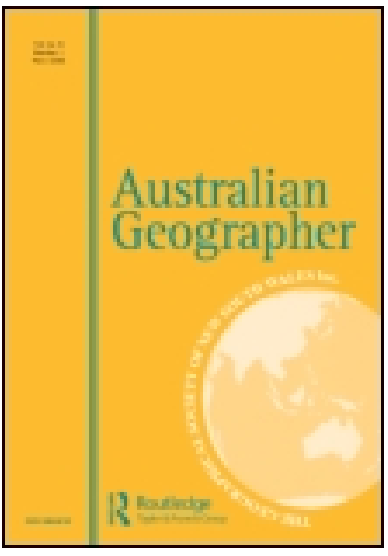

\title{
Australian Geographer
}

Publication details, including instructions for authors and subscription information:

http:// www. tandfonline.com/ loi/ cage20

\section{Indirect Tracking of Drop Bears Using GNSS Technology}

Volker J anssen ${ }^{\text {a }}$

a University of Tasmania, Australia

Version of record first published: 10 Dec 2012.

To cite this article: Volker J anssen (2012): Indirect Tracking of Drop Bears Using GNSS Technology, Australian Geographer, 43:4, 445-452

To link to this article: http:// dx.doi.org/ 10.1080/00049182.2012.731307

\section{PLEASE SCROLL DOWN FOR ARTICLE}

Full terms and conditions of use: http://www.tandfonline.com/page/terms-andconditions

This article may be used for research, teaching, and private study purposes. Any substantial or systematic reproduction, redistribution, reselling, loan, sub-licensing, systematic supply, or distribution in any form to anyone is expressly forbidden.

The publisher does not give any warranty express or implied or make any representation that the contents will be complete or accurate or up to date. The accuracy of any instructions, formulae, and drug doses should be independently verified with primary sources. The publisher shall not be liable for any loss, actions, claims, proceedings, demand, or costs or damages whatsoever or howsoever caused arising directly or indirectly in connection with or arising out of the use of this material. 


\title{
Indirect Tracking of Drop Bears Using GNSS Technology
}

\author{
VOLKER JANSSEN, University of Tasmania, Australia
}

\begin{abstract}
Animal tagging and tracking has been a fundamental tool in the quest to increase our knowledge and understanding of biogeography and ecology for about 50 years. Monitoring animal populations is also necessary for conservation purposes and to limit negative effects on the human population, particularly in an era of human expansion into traditional animal habitats. The use of Global Navigation Satellite System (GNSS) technology has been responsible for significant advances in this field by providing the ability to obtain accurate, regular and frequent estimates of the changing distributions of many rare animal species. Employing conventional GNSS-based animal tracking methods to study drop bears is extremely difficult due to their habitat. The dense tree canopy regularly causes extended periods of complete GNSS signal loss, and sensors are often damaged during attacks on prey. This paper proposes an indirect, GNSS-based method for tracking drop bears. This involves tracking the prey rather than the predator in order to map the population of drop bears in a particular area. The method can be used to effectively estimate the number of drop bears in the study area. Analysis of the collected data provides valuable insights into the hunting behaviour of drop bears and has implications for a better understanding of the geographical distribution of other rare species, including hoop snakes and bunyips.
\end{abstract}

KEY WORDS Animal tracking; biogeography; ecology; drop bears; GNSS.

\section{Introduction}

Australia is home to many unique animals, particularly monotremes (i.e. echidna and platypus) and marsupials such as the kangaroo, wallaby, koala, possum, wombat, drop bear and Tasmanian devil. Monitoring these animal populations is important to ensure their conservation and to limit negative effects on the human population (e.g. in the tourism and agricultural sector), particularly in an era of ever-increasing human expansion into traditional animal habitats. Several species, such as the Tasmanian devil, are presently declining, and others, such as the drop bear, are rarely seen. Hence this paper comes at a critical time in national history, when relatively little is known about indigenous species whose status may be threatened.

Animal tagging and tracking, i.e. the monitoring and recording of the animal's sequential positions, has been applied to the study of animal behaviour and ecology 
for about 50 years. Initially, tracking relied on VHF (very high frequency) radio technology. The disadvantages of this approach include the requirement of receivers being close enough to the animals to triangulate animal positions and the low temporal resolution of position fixes. Much also depended on whether the animals were listening to the radio at the time.

Significant advances were made with the advent of Global Navigation Satellite System (GNSS) technology, providing the ability to obtain accurate, regular and frequent estimates of locations for movement ecology research into many species of animals (Tomkiewicz et al. 2010). At first, only large vertebrates such as elephants (Douglas-Hamilton 1998) and bears (Schwartz \& Arthur 1999) were able to be tracked due to the considerable sensor size and the reliance on rather large, heavy battery packs. Technology improvements and the miniaturisation of equipment allowed the tracking of much smaller animals, including possums (Dennis et al. 2010) and pigeons (Steiner et al. 2000). In all these cases, the sensor is attached directly to the animal of interest.

This paper proposes an indirect, GNSS-based method for the tracking of drop bears. Rather than tracking the animals themselves, the prey is tracked to infer the location and size of the population. Using a case study, it is shown that this method can be used to effectively estimate the number of drop bears in the study area.

\section{Drop bears}

The drop bear (Thylarctos plummetus) is an arboreal (i.e. tree-dwelling), predatory marsupial that closely resembles the koala (Phascolarctos cinereus) and is therefore difficult to spot. Colloquially, it is often referred to as the carnivorous 'evil twin' of the koala because it is a vicious creature sharing a very similar habitat. Based on megafauna bones discovered in Aboriginal middens, it is believed that the two present species evolved from a single ancestor during the late Holocene. Theories that its dropping skills follow from genetic similarities with sugar gliders remain empirically untested.

The drop bear is a strongly built animal with powerful forearms and claws for climbing and holding on to prey. In stark contrast to the very similar looking but smaller koala, it has large canine teeth that are used very effectively as biting tools. It generally hunts during the day by ambushing ground-dwelling animals from above, skilfully latching onto the victim's neck to kill its prey. Quietly waiting in a tree for several hours, it closely resembles a sleeping koala. Once prey is within striking range, the drop bear will drop several metres out of the tree to pounce on top of the unsuspecting victim (see Plate 1). The initial impact generally stuns the prey, allowing it to be bitten on the neck and quickly subdued. The examination of kill sites and scats indicates that medium to large species of mammal make up most of its diet (Hosking 2012). Often, the prey is considerably larger than the drop bear itself. A nocturnal variation of the species (Thylarctos plummetus vampirus) has resorted to draining the prey of its blood rather than feasting on its flesh (Lestat 2010).

The drop bear is found mainly in coastal regions of eastern and southern Australia, stretching from the Cape York Peninsula to Tasmania. Populations also extend for considerable distances inland in regions with enough moisture to support suitable woodlands not limited to eucalypts. Woodland is crucial since drop bears are not easily able to drop from spinifex bushes and desert plants, while fewer 

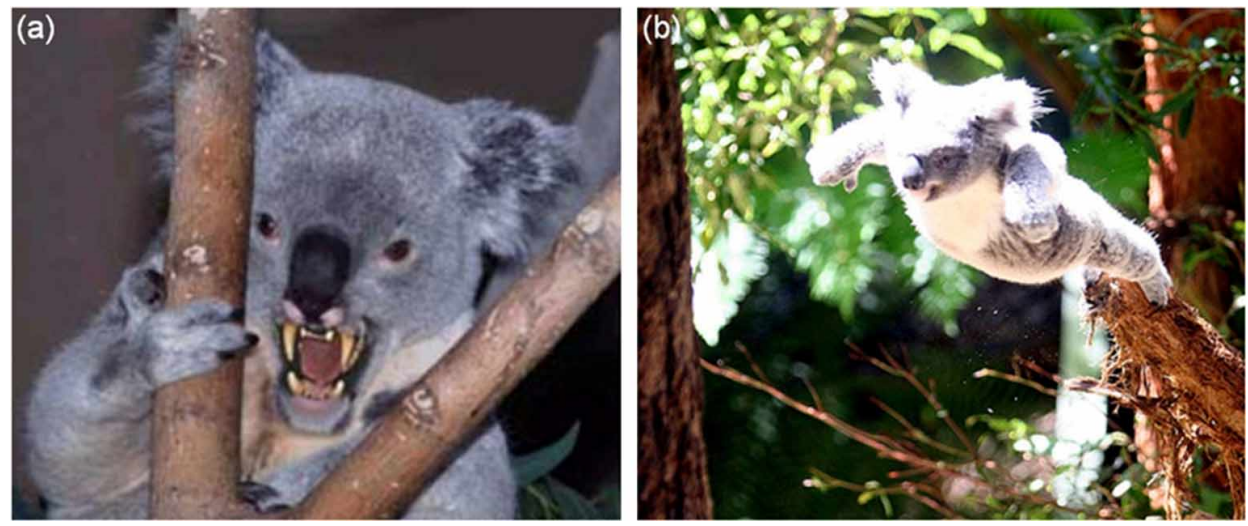

Plate 1. Drop bear (a) in its habitat and (b) attacking prey.

victims in more arid environments reduce the ability to work downwards through the food chain and thus lower survival rates. Reports of periodic attacks on opal miners in Coober Pedy may be apocryphal and related to excessive consumption of cooling amber fluids in dry areas. The distribution of drop bears across Australia is quantified by the National Drop Bear Index (NDBI), which indicates the average population density per $\mathrm{km}^{2}$ (see Figure 1). Aboriginal dreamtime legends suggest that the drop bear was once much more widespread, hence the need for contemporary conservation.

Unlike other peculiar Australian animals such as the bunyip and the hoop snake, which are rarely encountered in even thinly populated areas, drop bears pose a considerable risk to unsuspecting bushwalkers, particularly tourists, because they closely resemble the koala. While the Australian government has been accused of

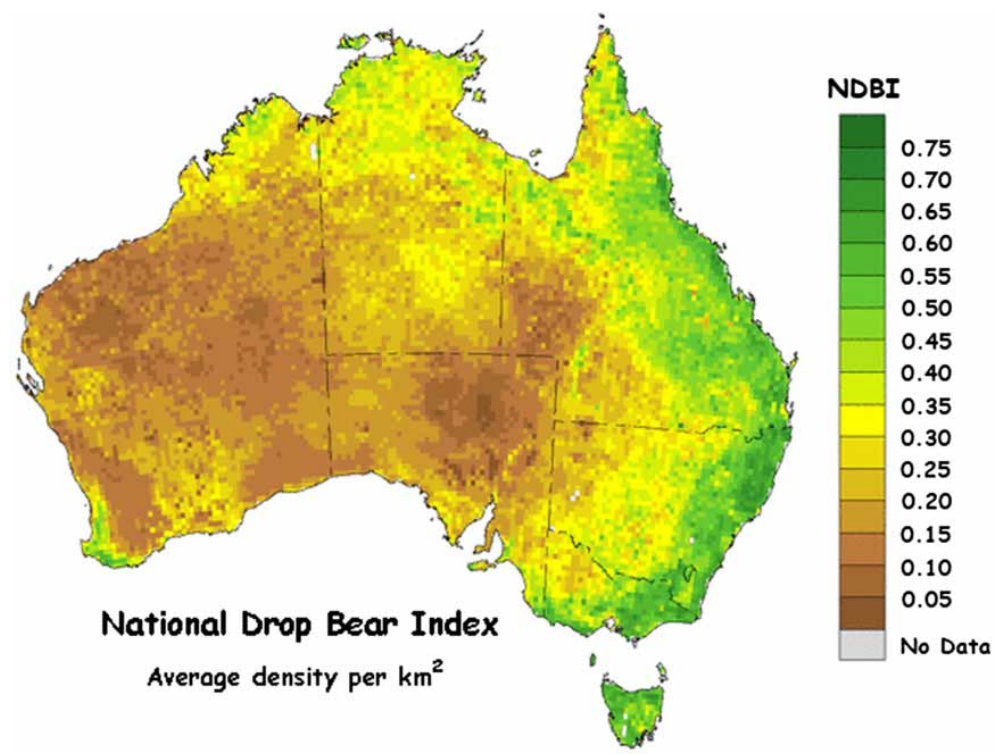

FIgure 1. Distribution of drop bears in Australia, quantified by the National Drop Bear Index (NDBI). 
orchestrating a conspiracy to cover up the existence of drop bears in order to protect the tourist industry (Langly et al. 1999), these claims have never been substantiated.

Drop bears do not target human beings specifically, but there have been several cases where humans have fallen victim to drop bear attacks, resulting in serious lacerations and even death. Disappearances which may (or may not) be attributed to drop bears have occurred frequently across Australia (e.g. Holt 1967; Hussey 1989; Mulder \& Scully 2000).

Several methods have been proposed to protect humans from drop bear attacks, although their effectiveness often remains scientifically inconclusive (e.g. Skywalker 2008). These methods include wearing forks in the hair, spreading vegemite or toothpaste behind the ears or under the armpits, urinating on oneself, and avoiding talking in a foreign language or an accent other than Australian.

Other studies have indicated that by-products of the interaction between chemicals found in vegemite and those found in human sweat repel drop bears (Honeydew 2003). Most Australians and immigrants who have lived in Australia for long periods of time tend to eat vegemite consistently (usually at least once a day), so exuding these chemicals through their skin permanently, and are thus protected. Visitors, on the other hand, do not have this 'natural' protection and are therefore advised to apply a liberal amount of vegemite to the skin, the most suitable area being just behind and towards the top of the ear because this area is prone to sweating and closest to the top of the head.

While it is recognised that more research is required, there is unmistakable evidence that tourists are much more likely to be attacked by drop bears than Australians. Genetic analyses suggest that this may be related to the Australian 'mateship' trait which extends to animals unique to Australia (Crikey \& Beauty 2008). Furthermore, it has been shown that drop bears can detect foreign languages and are prone to target the origin of such sounds, but using the Aussie lingo may fool the average drop bear (Stewart 2005). There are therefore important and unusual parallels with the equally rare invasive alien species, the Bundy bear, which similarly favours arboreal habitats and preys on tourists, especially young female blonde foreigners. However, drop bear attacks on humans are rare, mainly because Australians are familiar with drop bear ecology, tourists are deliberately diverted and reality TV survivor series are usually undertaken elsewhere.

Investigating the effectiveness of several methods of protection against drop bear attacks has shown that the best protection is achieved by wearing a motorcycle helmet when bushwalking in drop bear territory, although this may be impractical in tropical regions (Skywalker 2008). An accomplished method of determining whether a drop bear may be lurking in the flora canopy is to lie down beneath a tree and spit upwards. If a drop bear is sleeping above, it will most likely wake up and spit back (Young et al. 1981). However, this approach includes some risk, and the consequences can be devastating if drop bears are on the hunt for prey or are in the middle of the mating season. Bushwalkers are advised to exercise caution in areas frequented by drop bears, hence the value of the present research.

\section{Indirect GNSS-based tracking method}

Monitoring drop bears is essential to ensure that a sustainable animal population is maintained, while limiting the possibility of attacks on humans. Employing 
conventional GNSS-based animal tracking methods (e.g. Dennis et al. 2010; Tomkiewicz et al. 2010) on drop bears is extremely difficult due to their habitat. Drop bears spend most of their time in treetops, resulting in extended periods of complete GNSS signal loss. Due to the viciousness of the animal (even under sedation), there is a considerable risk of injury when the sensor is attached. In addition, the GNSS sensor is prone to severe damage and loss during attacks on prey and due to the drop bear's habit of rubbing its body against tree branches. This severely reduces the availability of meaningful tracking data and substantially increases the cost of drop bear tracking.

In order to avoid these disadvantages, an indirect GNSS-based approach is proposed. This indirect method involves tracking the prey rather than the predator, thus pinpointing the location and timing of drop bear attacks in order to map the population of drop bears in a particular area. Drop bears are known to be very territorial and generally do not stray far from a relatively small number of trees, located in close proximity, that are used as a hunting ground. Hence the location of attacks provides a good indication of where drop bears reside.

\section{Case study}

A case study was used to demonstrate the effectiveness of the proposed indirect GNSS-based tracking method for drop bears. The study area was located in the northern part of Morton National Park, about $120 \mathrm{~km}$ south-west of Sydney. The indirect tracking method was used to estimate the number of drop bears inhabiting this area.

Several research assistants (mainly thrill-seeking international students in dire need of financial support) were equipped with GNSS sensors to track their position during bushwalks off the beaten track. The GNSS sensors utilised the differential positioning technique to provide high-quality real-time positioning solutions relative to a continuously operating reference station (CORS) nearby. Heavy-duty bike helmets and neck protectors were worn by all data gatherers to guard against potential injuries.

The fieldwork was undertaken on seven consecutive days starting on 1 April 2012. At times, dense tree cover caused some tracking problems and subsequent data gaps. However, due to the application of the differential positioning technique and the availability of the full GPS and GLONASS constellations, coordinate solutions along the paths taken by the data gatherers were generally accurate at the decimetre level or better.

The GNSS trajectories of the bushwalkers were used to determine the location (and timing) of drop bear attacks. An example of two typical tracks culminating in an attack is shown in Plate 2a, while a map illustrating the spatial distribution of all drop bear attacks observed is shown in Plate $2 b$. It can clearly be seen that the attacks appear in distinct clusters, indicating that six drop bears were involved and leading to the conclusion that at least six drop bears inhabit the study area. The timing of the attacks (data not shown) supports this conclusion. This suggests an otherwise unrecorded phenomenon of group attacks by families, mates or the marsupial equivalent of bikie gangs.

An examination of kill sites and scats in the study area was conducted a month before and after the GNSS field work was carried out. This provided an 


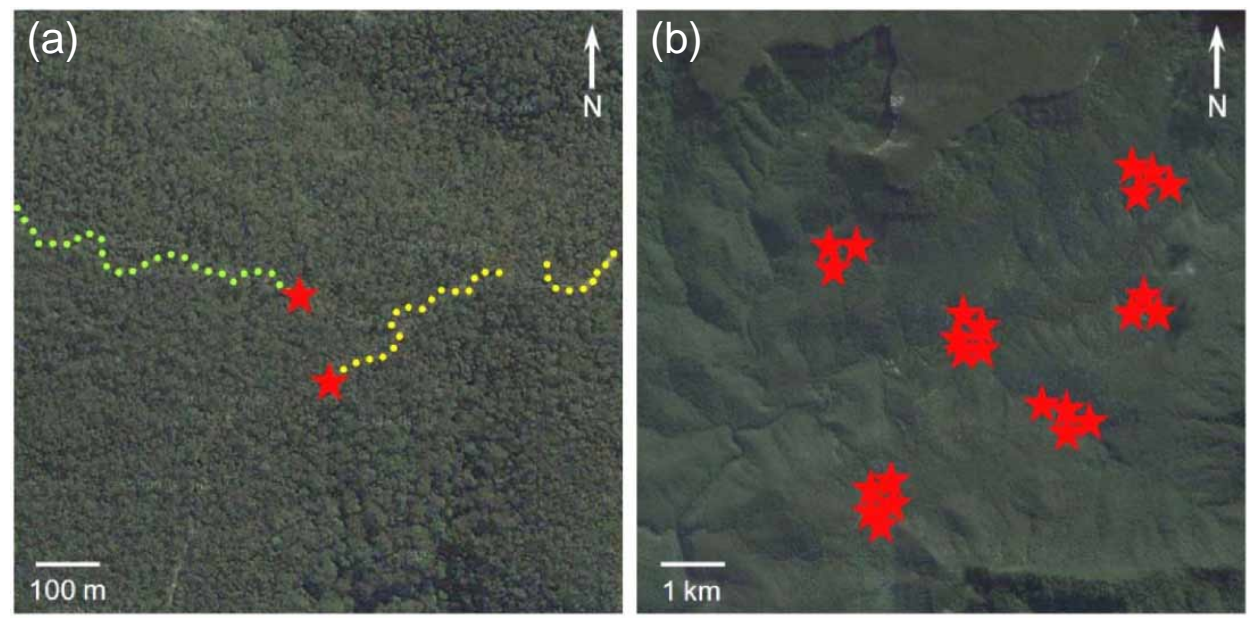

Plate 2. (a) Example of two GNSS tracks ending with a drop bear attack (denoted by a star), and (b) summary of all drop bear attacks observed.

independent method of estimating the number of resident drop bears and confirmed the findings obtained using the indirect GNSS-based tracking method.

In an additional investigation, pairs of data gatherers bushwalked along the same path in order to examine whether foreigners were more prone to drop bear attacks than locals. In the first scenario, an Australian was followed at a distance of about 50-100 $\mathrm{m}$ by an international research assistant. In the second scenario, the two data gatherers would swap positions.

While the relatively small data sample collected precluded rigorous scientific analysis, some general comments can be made. In both scenarios, Australians were far less successful in being 'dropped on' than foreigners. Only 10 per cent of Australians were targeted in the event of a drop bear attack. It was later discovered that those Australians were not fond of vegemite, lending further weight to Honeydew's (2003) incisive analysis. The results further indicate that drop bears do not necessarily target the last person walking in a line. However, more research into the behaviour of drop bears is required in order to confirm these findings, which may reflect seasonality and the presence of alternative nutrition.

It should be noted that no animals were harmed during this case study. Likewise, none of the bushwalkers were injured, with the exception of occasional lacerations and the severe bruising of egos, which were graciously endured in the name of science.

\section{Concluding remarks}

This study is invaluable as one of the very few geographical analyses of rare and endangered, if not always vicious, animals (Llwyd 1968; Johnston 1999; King et al. 2007). It has presented an indirect method of tracking drop bears using GNSS technology. Rather than tracking the animals themselves, the prey is tracked in order to map the location and size of the drop bear population. It was shown that this method is effective in both determining the number of drop bears present in the study area and accounting for their particular nutritional targeting preferences. The case study thus provided valuable insights into the hunting behaviour of drop bears, 
confirming that foreigners are much more likely to be attacked than Australians. Bushwalkers should be vigilant when hiking along less-frequented paths in Australia and take precautions in areas known to be inhabited by drop bears, where conservation practices can now be enhanced. Vigilance is vital as long as deforestation and habitat destruction exist close to tourist destinations. Until further research has been undertaken, it is essential that CSIRO's Drop Bear Aware campaign remains in place.

This bush pathbreaking research has begun to provide a much better understanding of the ecology of the drop bear. For reasons that were unclear but reflect the parlous position of field science funding in Australia generally, funding was unfortunately unavailable to extend the research into either other seasons or field sites (which would have enabled research on the particularly rare Tasmanian Snow Drop Bear). Further research would not only enable a better understanding of drop bears and even their previously much misunderstood mating habits (which may show that particularly violent drops on rather large tourists are really elaborate courtship displays), but would also enable a better understanding of the geographical distribution of other rare Australian species, including hoop snakes, bunyips and gravel sharks. At this point, the research has begun to indicate parallels with Bundy bears, but there are certainly hints that future multinational research on Bali dragons and British drop badgers may enable important conclusions of global significance on international genetic diversity. Thus far this research, with very little funding, has made a small contribution to Australian biogeography, itself seemingly a rare, declining and endangered species.

\section{Acknowledgements}

I would like to acknowledge John Connell for providing invaluable comments and suggestions during the preparation of this paper.

Correspondence: Volker Janssen, School of Geography and Environmental Studies, University of Tasmania, Hobart, Australia.

E-mail: volker.janssen@utas.edu.au

\section{REFERENCES}

Crikey, O. \& Beauty, U. (2008) 'Genetic fingerprinting reveals mateship traits in Australian animals', Budgie Smuggler 31(5), pp. 29-36.

Dennis, T.E., Chen, W.C., Koefoed, I.M., Lacoursiere, C.J., Walker, M.M., Laube, P. \& Forer, P. (2010) 'Performance characteristics of small global-positioningsystem tracking collars for terrestrial animals', Wildlife Biology in Practice 6(1), pp. 14-31.

Douglas-Hamilton, I. (1998) 'Tracking African elephants with a global positioning system (GPS) radio collar', Pachyderm 25, pp. 81-92.

Holt, H.E. (1967) 'The art of disappearing without a trace', fournal of Discoveries 18(5), pp. $116-25$.

HONEYDEw, B. (2003) 'Understanding the chemical interactions between vegemite and human sweat', Fournal of Irreproducible Results 45(13), pp. 407-19.

Hosking, C. (2012) 'Animal species: drop bear', available from: http://www.australian museum.net.au/Drop-Bear (accessed 16 July 2012).

Hussey, W. (1989) 'What really happened during the picnic at Hanging Rock?', Victorian fournal of Montane Mystery 17(9), pp. 246-51. 
Johnston, R. (1999) 'Classics in human geography revisited', Progress in Human Geography 23(2), pp. 253-66.

King, A.M., Cromarty, L., Paterson, C. \& Boyd, J.S. (2007) 'Applications of ultrasonography in the reproductive management of Dux magnus gentis venteris saginati', Veterinary Record 160, pp. 94-6.

LANGLY, R., Frohike, M. \& Byers, J.F. (1999) 'The truth is out there: a government conspiracy covering up the existence of drop bears in Australia', The Lone Gunman 12(7), pp. $15-21$.

Lestat, V. (2010) 'At dawn they sleep: allies in the Australian animal kingdom', Australian Vampire Chronicles 219(7), pp. 255-64.

LLWYD, L. (1968) 'A preliminary contribution to the geographical analysis of a Pooh-scape', IBG Newsletter 6, pp. 54-63.

MuldeR, F.W. \& Scully, D.K. (2000) 'Connections between alien abductions and drop bear attacks in Australia', fournal of Paranormal Phenomena 8(3), pp. 52-68.

SCHWARTZ, C.C. \& ARTHUR, S.M. (1999) 'Radio-tracking large wilderness mammals: integration of GPS and Argos technology', Ursus 11, pp. 261-73.

SKYwALKER, L. (2008) 'May the force be with you: a study on the protection from drop bear attacks', Clone War Chronicles 22(4), pp. 213-25.

Steiner, I., Bürgi, C., Werffeli, S., Dell’Omo, G., Valenti, P., Tröster, G., WOLFER, D.P. \& LiPP, H.P. (2000) 'A GPS logger and software for analysis of homing in pigeons and small mammals', Physiology and Behavior 71(5), pp. 589-96.

STEWART, A. (2005) 'Stone the flaming crows: drop bears and the Aussie lingo', fournal of Australian Linguistic Anomalies 7(3), pp. 48-59.

Tomkiewicz, S.M., Fuller, M.R., KIE, J.G. \& BAtes, K.K. (2010) 'Global positioning system and associated technologies in animal behaviour and ecological research', Philosophical Transactions of the Royal Society B: Biological Sciences 365(1550), pp. 2163-76.

Young, M., Young, A. \& Johnson, B. (1981) 'For those about to spit (we salute you)', Rock Paper Scissors 9(2), pp. 33-41. 